\title{
Priorities in care and services for elderly people: a path without guidelines?
}

Åke Bergmark, Marti G Parker and Mats Thorslund Stockholm University, Stockholm, Sweden

\begin{abstract}
The growing gap between demands and resources is putting immense pressure on all government spending in Sweden. The gap is especially apparent in care and services for elderly people in light of the rapid aging of the population. The article considers the decisions and priorities concerning resource allocation in the welfare sector in general and in elderly care in particular. The aim is to describe the political and administrative setting and to provide a conceptual structure that outlines the nature of the problem. Various levels of decision making are identified and discussed in the context of political accountability. Current transitions in elderly care are described with respect to service provision, marketisation, coverage rates, and eligibility standards. Basic principles of distribution are highlighted in order to clarify some central concepts of efficiency and justice, and a number of strategies for actual prioritising are identified. The article concludes with an endorsement of more conscious decisions in resource allocation. Existing knowledge and information concerning the effects of various strategies must be utilised, and the values and assumptions used for setting priorities must be made explicit.
\end{abstract}

(Fournal of Medical Ethics 2000;26:312-318)

Keywords: Resource allocation; elderly people; ageing populations; care of the elderly; welfare; priority setting

\section{Introduction}

In the dictionary, the definition of prioritise is to rank in a sequential order or to give precedence. Priorities are about making choices when the perceived need or demand exceeds available assets. In this sense the concept is closely related to the very core of economics or politics. A classical definition of economics is that it deals with the allocation of limited resources with alternative uses. An equally well-known definition of politics is that it is about "who gets what and under what circumstances". ${ }^{1}$ According to these definitions, issues of allocation or making priorities in the public sector belong equally to economics and politics However, neither economic theory nor political science provide sufficient tools for any descriptive or normative analysis of how priorities are or ought to be made. To understand allocative principles, we must also include the basic values at hand and how they are shaped through political and economic reality.

This article raises issues concerning resource allocation and priorities with relevance for elderly care in Sweden. We begin with the fact that this area-in the crossfire between a growing number of elderly people and decreasing resources-is facing substantial challenges. Today we see, however, very few conscious strategies or systematic approaches for dealing with these challenges. One reason for this is that political accountability is diffuse, another reason is that vital concepts of distributive justice are blurred in the everyday political debate.

Our aim is to provide a conceptual structure that outlines the nature of the problem. The main focus is on the situation in Sweden, but the problems discussed are of a general nature and are relevant to most other welfare states. We will briefly describe the Swedish system of care, pinpoint the strategic levels of decision making and analyse the various preconditions for setting priorities.

\section{The Swedish welfare state}

The Swedish welfare system has long served as an archetype of the modern welfare state: bearing the traits of universality, high taxation, and social security programmes which reach a large proportion of the population. It has also been associated with a continual expansion. With the beginning of the 1990s, economic recession, increased unemployment and a rapidly growing national deficit have jointly swept away the financial base for further expansion. Instead, national and local authorities have had to make cutbacks in many areas. The welfare sector, representing a major part of public spending in Sweden, has been an obvious target.

The onset of the financial problems coincided with a debate that questioned the legitimacy and rationality of the welfare state. The critique focused on an alleged lack of efficiency and unintended side effects of welfare policy in general and certain programmes in particular. ${ }^{3}$ Public support for a comprehensive welfare system decreased during the 1980 s. ${ }^{4}$ It was widely argued that private entrepreneurs and an increased utilisation of market mechanisms could offer an alternative to the traditional Swedish model.

The efforts to bring down the national deficit have been rather successful in monetary terms. However, the welfare cutbacks have resulted in lowered compensation levels, less generous eligibility standards and decreased quality of care. The reactions to this have primarily been negative. Media exposure of people suffering from the changes, protests from trade unions, and public expressions of dissatisfaction have followed the 
Figure 1. Popular opinion on the Swedish public sector[5]

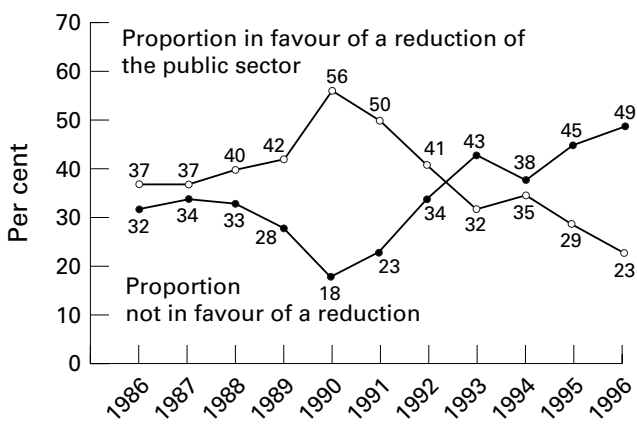

rationing measures. As a consequence, public opinion has turned back in favour of a strong tax-financed welfare sector. Figure 1 depicts the dramatic changes in public opinion over the past ten years. Until 1988 public opinion was fairly stable and polarised, with as many people in favour of preserving the public sector as there were people in favour of reduction. In 1990 the support for a decrease was three times higher than the support for preservation. From then on, there has been a steady trend toward increased support for the public sector. In 1996 the percentage in favour of a diminished public sector was lower than ever before. This development coincided with a likewise dramatic drop in support for private provision of care and other, traditionally publicly organised, services. $^{5}$

One of the reasons behind the increased support, suggested by Svallfors ${ }^{6}$ is that the middle class, as a result of the crisis, has become aware of its economic vulnerability. When facing the risk of unemployment or personal financial responsibility for different welfare services, people are likely to support a strong welfare sector. Another explanation, suggested by Möller, ${ }^{7}$ is that there is a tendency for any status quo to harden into a right, ie, what was once a generous social benefit becomes perceived as an entitlement.

There is, however, a difference between public and elite discourse. Attitudes are hardly mediated directly from "the masses" to opinion or actions of the leading elite. ${ }^{8}$ In Sweden, the political and economic elite displays a somewhat more negative attitude towards the public sector. In the last few years, however, there has been a visible trend towards increased support even among the elite, ${ }^{6}$ which is not surprising, considering the dramatic changes in public attitude and the political need for popular support.

\section{The system for providing care services for elderly people}

Two major state laws guide the provision of care in Sweden. The Health and Medical Services Act of 1983 maintains that medical care shall be available to all members of society, regardless of income, age or residence. The Social Services Act of 1982 grants individuals of all ages assistance with livelihood and other aspects of living if their needs cannot be provided for in any other way. These laws are of a framework nature; they include some elements of detailed regulation but allow for local autonomy in decision making. ${ }^{9} 10$

The Swedish welfare sector has enjoyed continuous expansion during most of the postwar period. The system has developed a wide spectrum of services; social services include child day care, home help for elderly and disabled persons, and general social services for individuals and families. Medical services include primary and hospital care as well as subsidised prescription drugs and technology. Most services are either free or heavily subsidised; the system is financed through a combination of direct taxation and employer fees. The role of private and volunteer services has, in comparison with other countries, been minimal. While there is a strong feeling among the general public that it is ultimately the state's responsibility to care for old people, there is still a substantial amount of informal care provided by family members, friends, and neighbours. The extent of this care is difficult to assess, but it is obvious that it forms the bulk of all care given. ${ }^{11}$

In general, the county councils of Sweden are responsible for medical care, while the municipalities are responsible for social services. However, when considering the needs of elderly people, the division between medical care and social services is ambiguous. The Elderly Reform Bill of 1992 transferred the responsibility for long term care, including nursing homes, to the municipalities and opened up the possibility of municipalities providing primary care and home medical care for elderly people. Therefore, it is difficult to separate medical care and social services for elderly people. In Sweden the two sectors are inextricably intertwined.

\section{Transitions}

Sweden leads the world's nations in the proportion of persons over the age of 65. Although it is speculated that Japan will surpass Sweden in coming years, Sweden will continue to lead for many decades in the proportion of persons over the age of 85 , that is, the sector of the population with the greatest needs. ${ }^{12}$ For this reason, the transitions that Sweden is currently experiencing may well foreshadow future developments in other countries.

While Sweden's welfare policy is characterised by the concept of universality, there has always been an acceptance of needs assessment for many social services. The Social Services Act implies means testing for eligibility with the statement "grants assistance if needs cannot be provided for in any other way". This statement gives the municipalities much leeway for interpretation. And Swedish municipalities are making use of this leeway: the thresholds in both needs assessments and means testing are being raised. An individual must have greater need and less means to qualify. There are extreme differences between the municipalities 
when it comes to coverage rates, eligibility criteria and fees for services, as well as quality of service. ${ }^{13}$

One pattern seen in most municipalities is the tendency to concentrate resources on people with the most extreme needs. For example, in the seventies it was common to provide elderly people with household services such as shopping and cleaning, even if they had no severe disabilities. The fact that these tasks were difficult for an individual was enough to warrant the services. There was also a social aspect to eligibility, sending a home helper to an old person was a way to prevent social isolation. Eligibility criteria today are much stricter. Most home help recipients today are quite disabled; they need extensive help with personal care as well as household tasks. Municipalities are also increasing their fees for services, in another attempt to decrease demand.

This trend is concurrent with the trend to de-institutionalise long term care. In fact, the term "institution" has been replaced with the term "special housing". In an effort to decrease costs, the eligibility criteria for special housing beds have increased; nearly all people now entering long term special housing are demented. This puts even more pressure on the services which provide care in the home, as the community-based population of elderly persons now includes very disabled persons who would have been in institutions a decade ago. Thus the characteristics of the community-based elderly population and the institutionalised popula-

Figure 2. Percentage of elderly persons receiving home help and in special housing

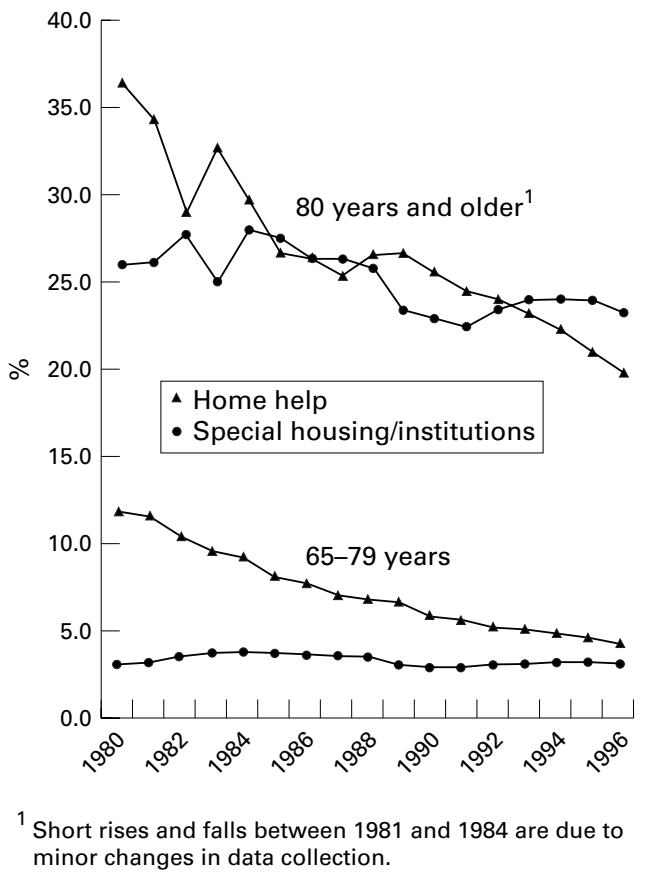

tion have shifted: both groups now have a greater proportion of people with physical and cognitive disabilities.

Figure $2^{14}$ illustrates the decrease in the proportion of elderly persons receiving either home help or special housing (including hospitals). Conversely, there is an increase in the proportion of persons receiving no services at all.

Another trend is the movement towards the privatisation of care services. Whereas municipalities previously financed and provided most services, they have begun to contract out some services, including nursing homes, to private firms. The services continue to be financed by the municipalities, and the municipalities continue to be responsible for the quality of services, but private firms manage the actual provision. Today, around nine per cent of long term care and about three per cent of home help services are provided by private firms. ${ }^{15}$

Although it is not possible to predict the exact number of dependent elderly persons in the future, all available data points to a substantial increase in the number of the oldest old, and with that, a substantial increase in the care needs of this sector of the population. The combination of an economic decline and an aging population constitutes a dilemma that is shared by most industrialised countries today. A growing disparity between needs and resources puts immense pressure on government spending and highlights the need for allocative strategies. "Priorities" is very much the word of the day, however, neither national nor local politicians have articulated ideas of how-by what strategies or principles - these priorities should be made in practice.

\section{The formation of policy: structure of influence and levels of decision making}

The need to set priorities is by no means a new phenomenon or an isolated consequence of financial constraints. In reality, priorities have always been set at different levels in allocative decision making. In practice, however, allocation and general policy making rarely correspond to any clear cut set of priorities. The political processes are shaped through a complex pattern of manifest ambitions, tactical considerations, compromise and political horse-trading. Empirical findings show that although most decision makers have direct personal experience of rationing measures and acknowledge the need for well-judged priorities, very few are fully aware of how or on what grounds they actually make their decisions. ${ }^{16}$

The structure of formal political influence in Swedish social services organisations and health care allows a number of decision makers on different levels to exercise control over the distribution of resources. A distinctive feature of Sweden, and other Scandinavian countries, is that local government activities represent a significantly higher share of public consumption than in other industrialised countries. ${ }^{17}$ A consequence of this is that the local sector in Sweden is a more central arena for welfare 
provision and that decisions on the local level are substantially more influential. National government has, however, a considerable influence through legislation and state subsidies to the municipalities. The impact of the legislative action is a function of how detailed and directed the laws are in their construction. A very detailed legislation leaves less scope for decisions on subordinate levels, while framework laws give local government and professionals more command of resources and interpretation of policy.

Who then are the actors involved in the allocative processes? For elderly care, the overall distribution of resources rarely corresponds to a single decision or an identifiable political responsibility. Elected bodies at national, county, and municipal levels all exercise power and jointly set the standards for care. Furthermore, executives, administrators and care-giving professionals have scope to act within the framework set by the politicians. To simplify matters, it is easier to speak of levels of decision making than to try to identify all relevant actors.

In previous discourse on allocation, a distinction between first- and second-order decisions has been suggested. ${ }^{118}$ First-order decisions represent political decision making concerning the total quantity of resources distributed to various sectors. Secondorder decisions refer to decisions regarding the allocation of given resources among potential users. Expanding a structure like that to the actual political and administrative setting of Sweden, four levels of decision making may_roughly—be identified:

1. National political decisions through legislation and state subsidies;

2. Allocation between different sectors at the municipal level (for example: between social services and other municipal sectors);

3. Decisions/priorities regarding different activities within a sector (for example, between elderly care and other social service sectors);

4. Decisions/priorities regarding individual users within a specific activity.

In real life there are no clear cut dividing lines between the different levels. Decisions higher up may have substantial consequences for priorities on subordinate levels. The practice carried out on the last level may call for action at national level.

In fact, national government decisions often explicitly aim to change the division of responsibility. A recent example of this is the previously mentioned Elderly Reform Bill of 1992 that delegated more responsibility for elderly care from the county councils to the municipalities.

Consequently, the extent of influence or responsibility is by no means fixed, but rather an object for political change in itself. The actual content and relative weight of the different levels is in many respects a function of political will. In Sweden, it is difficult to pinpoint where the ultimate responsibility for elderly care is located. The national government is formally accountable for all societal conditions, including health and welfare provided by county councils and municipalities. However, the local authorities make most of the actual decisions on levels 2,3 and 4 . In situations where local opinion finds the care provided to be unsatisfactory, or when there are reports of maltreatment, the locus of perceived responsibility seems to be a function of the occurrence or frequency of the problem. The less common the reports of undesirable conditions are, the more the focus is directed towards the local authorities and the more widespread the problems seem to be, generally speaking, the more the attention is directed towards national government. The same mechanisms are also present within the local settings. Isolated incidents of maltreatment may often be attributed to shortcomings of the caregiving staff or care-giving units, while more extensive problems call for action from the municipal and county councils. On the whole, however, accountability is very diffuse-making it easy for politicians to deflect responsibility away from themselves when convenient.

\section{Principles of distribution}

So, what are the principles, mechanisms or assumptions being employed as the Swedish welfare state puts the brakes on expansion? In the initial stages of the financial constraints, political first-order decisions have emphasised efficiency aspects. The idea of increasing efficiency has an obvious attraction since, at least rhetorically, it offers an alternative to the arduous and controversial task of rationing. Striving for efficiency and giving efficient activities priority over ineffective ones are natural first steps. Making cutbacks in resources in sectors with dubious efficiency may serve two purposes. Firstly, it may be an incentive to improve overall efficiency and to refine organisational solutions. The general supposition is then that the same level of care can be achieved with fewer resources. This reflects the concept of raised productivity. Secondly, decisions about cutbacks may rest on an assumption that the resources on the margin of a programme might be reduced without any harm to what is considered its central task or "core" function. Conversely, any addition of resources should primarily be put where they produce the greatest increment of welfare.

Reference to efficiency is, at the moment in Sweden, a standard component of political language and explicit political motives in any discussion concerning the "hows" and "whys" of resource allocation. A fundamental, but rarely acknowledged, problem in this context is that most decision makers have a very vague idea of what constitutes true efficiency, quality or marginal utility in care or welfare provision.

A concept or value that most actors are prepared to embrace-at least in its most common and unspecific form-is justice. Justice concerning the allocation of goods and burdens is often referred to as distributive justice. ${ }^{19}$ The more articulated principles of distributive justice, sometimes called material principles of distribution, ${ }^{20}$ explicitly tell us what circumstances should be regarded as relevant 
and when exceptions from an equal distribution may be legitimate. Three material principles of distribution embody most notions of just distribution in welfare provision:

- the principle of need

- the principle of merit

- the principle of contribution or just possession

In various ways, all these principles have made their mark in current discussions of the allocative strategies for welfare in Sweden. To some extent, the principle of need has been the most central. This principle incorporates the idea that resources should be allocated on the basis of need and, consequently, that extensive or more severe needs should serve as grounds for high priority. The concept of need is central in many of the more comprehensive and general theories concerning justice. ${ }^{202}$ In prioritising, the principle of need is used when emphasising the conditions for vulnerable groups. Decision makers differ, for ideologica reasons, in how much this is stressed and in what groups are identified as having the most severe needs. Need, far from being an unambiguous concept, is in many respects apt to create disagreemen among different actors. ${ }^{23}{ }^{24}$ Notions of need materialise in any decision about which needs are to be met and to what level services should be provided. In many areas demand serves as a proxy for need.

A somewhat disparate principle of distribution is the principle of merit. Merit implies that resources, at least to some extent, should be allocated in order to reward achievement or morally desirable behaviour. This principle has an instrumental as well as a moral side. The former is related to the concept of incentives: if eligibility for welfare services requires certain achievements or modes of behaviour, individuals are expected to act in certain ways in order to qualify. The moral side - which is the most significant here-is linked to the concept of desert. With this, the idea is to reward individual sacrifice and effort without any regard to incentive effects. In general, this is more often applied to cohorts than to individuals. ${ }^{26}$ It is a central notion in arguments in favour of maintaining the welfare of elderly people, for example, "those who have built up our welfare society have the right to enjoy the outcome of it".

The most market-oriented principle is the principle of contribution or just possession-a line of thought that is central in most of the currently influential conservative theories of justice, for example, those of Nozick. ${ }^{27}$ According to this principle, welfare services should be distributed in relation to how much the citizens have contributed to their financing. Private insurance schemes (instead of universal tax-based systems) and the use of fees for services are examples of this principle. Public responsibility for care or income maintenance should be kept at a minimum and the individual should pay for all "extras". In recent years, the use of fees has increased in services for elderly and disabled people in Sweden. ${ }^{28}{ }^{29}$
The basic values or principles determining allocation are difficult to identify with empirical research. A recent Swedish study of decision makers suggests that various interpretations of need seem to precede inclinations to prioritise elderly care ahead of other social services sectors. ${ }^{15}$ Perceptions of merit, ie, that elderly people collectively deserve good care because of their past contributions to society, were quite common but had no influence on the tendencies to prioritise the elderly care sector.

\section{Structures of selection and strategies of execution}

If considerations of efficiency and principles of justice correspond to the question of "why?" in prioritising, the issue of "how?" implies somewhat dissimilar elements. Basically two factors are central to understanding the nature of how priorities are carried out: structures of selection and strategies of execution. Structures of selection refer to how different targets (programmes etc) are identified and how they are ordered sequentially in allocative considerations. Assessments concerning welfare allocation are, however, rarely made explicit in a sense that allows insight into actual rankings. Political processes are, furthermore, by nature complex and thus hard to capture within general structures. On a theoretical level, however, it is possible to imagine four basic forms of structures of selection:

Positive priorities: to identify sectors, services or recipient groups that should be given precedence; Negative priorities: to identify sectors, services or recipient groups with the lowest degree of urgency; Full range priorities: to establish a full rank in sequential order - from highest to lowest priority between sectors, services or recipient groups;

Positive - negative priorities: a combination of alternatives 1 and 2, where areas of high and low priority are identified, but no full rank order is established.

Of these forms, full-range priorities are the least common in actual decision making. The more thorough an order of priority is, the greater the expectations of explicit motives and a reliable knowledge concerning the areas affected. Attempts to establish full ranks in sequential order are therefore rare.

Positive priorities, on the other hand, are probably the most common and most frequently found in political rhetoric as well as in actual allocative decisions. At this time, elderly care is undoubtedly the one area in the welfare sector that most actors, politicians and the public ${ }^{16}$ want to give the highest priority. This has mainly been manifested as opinions, although a number of political promises to increase the resources for elderly care have been made recently at national and local levels.

Negative priorities or positive-negative priorities do occur, but are less likely to be publicised by 
decision makers. Most decision makers, for strategic reasons, are unwilling to be specific when it comes to the objects of rationing. As mentioned above, there is a tendency for any status quo to harden into absolute rights (as far as the recipients are concerned) which makes cutbacks in welfare unpopular. Politicians want to be re-elected and take great care not to express motives that "deny" the needs of certain groups. Elderly care in general is not an object of negative priorities, however, there are differing opinions concerning which services or programmes within the sector should be cut back or replaced by private or informal resources.

"Strategies of execution" refers to how priorities are managed in practice. There are a number of different responses to economic cutbacks. Some of these may be characterised as efforts to avoid the unpleasant task of making priorities-increasing public income or overall efficiency are the most obvious solutions. The scope for handling the current economic problems in Swedish welfare with such measures is, however, restricted. Cutbacks seem to be inevitable and there are basically two ways to tackle the situation:

- to maintain a constant supply of services but decrease or radically alter the quality of services provided; or

- to discontinue or reduce certain services.

Both of these strategies imply allocative cutbacks and-in general-deteriorated conditions for specific recipient groups. They are rarely explicitly acknowledged or articulated openly in the political process. The former strategy has, during the 1990s, been a course of action widely practised in order to reduce resources in child day-care, where the costs have decreased but the coverage rates remained the same. Bergmark ${ }^{28}$ refers to this process as dilution. An assumption here is that resources on the margin of a programme might be reduced without any harm to what is considered to be the central task or core function.

In elderly care, it is primarily the latter of the strategies above-discontinuation or reduction of certain services - that has been exercised. This is referred to as focusing. ${ }^{28}$ As was demonstrated in figure 2, younger and comparatively healthier pensioners are receiving less help, less money is spent on home help services, and increased resources are transferred to institutional care. What we see are processes where eligibility for the least needy is decreased, while others may receive consistent or even improved services.

\section{Conclusions}

The fact that the Swedish population is aging is one measure of the success of Swedish social policy over the past half century: more individuals than ever before have been able to live well past retirement. The vast majority of pensioners are healthy and independent, with little or no need of social and medical services. However, the need for services does increase with age, and especially in the highest age groups there is a substantial increase in needs. As the proportion of old people in the population increases, the needs for services will necessarily increase. Unless there is a corresponding expansion of resources, which seems unlikely, steps will have to be taken to make better use of existing resources and to set priorities for allocating resources.

Simultaneous with this growing gap between care needs and resources, the social and political environment in Sweden is becoming increasingly complex and diverse. The decentralisation, as emphasised in the Elderly Reform Bill of 1992, and the introduction of alternative providers (private, informal, and volunteer) are examples of this diversity.

There are few guidelines for introducing efficiency measures or for setting priorities. We really know very little about the consequences of various methods of distributing care resources in regards to the quality of care services, the formation of social inequalities, and the preservation of democracy. Priority committees within the medical services around the world have only succeeded in agreeing on some activities that should receive low priority in tax-supported medical systems, activities that are marginal at best in the larger economic perspective. A national framework for prioritisation in the medical sector in Sweden was suggested by a parliamentary commission in 1995. This framework has, however, no legal status and does not include social services for the elderly. ${ }^{29}$

The Health and Medical Services Act and the Social Services Act establish the goal of providing security for all members of society. Swedish constitutional law upholds the Swedish commitment to democracy. Therefore, this basic legislation gives us a general idea of where we want to go, but it does not provide the guidelines necessary for the concrete decisions that are being made concerning the distribution of resources.

To provide security, and to preserve the democratic process, we have to make conscious decisions, not impulsive reactions to crises. We must also understand the assumptions underlying the decisions. Existing knowledge and information concerning the effects of various strategies must be utilised. More knowledge must be accrued through systematic documentation and evaluation in order to develop more effective and efficient strategies - at all decision making levels. In other words, we should be continually asking ourselves, who is making what decisions and why?

\section{Acknowledgement}

This work has been developed within the context of the European Biomedical Ethics Practitioner Education Project (European Commission Contract No BMH4-CT96-0972).

Ake Bergmark, PhD, is Associate Professor of Social Work in the Department of Social Work, Stockholm University, Stockholm, Sweden. Marti G Parker, PhD, is Assistant Professor of Social Work in the same 
318 Priorities in care and services for elderly people: a path without guidelines?

department and Mats Thorslund, PhD, is Professor of Social Work, also in the Department of Social Work at Stockholm University.

\section{References}

1 Elster J. Local justice. How institutions allocate scarce goods and necessary burdens. New York: Cambridge University Press, 1992.

2 Ferge Z, Kolberg JE, eds. Introduction-social policy in a changing Europe. Social policy in a changing Europe. Frankfurt am Main and Boulder: Campus/Westview, 1992.

3 Lindbäck A. Welfare state disincentives with endogenous habits and norms. Stockholm: Industrial Institute for Economic and Socia Research, 1995

4 Hadenius S, Nilsson L. Ifrågasatt. Den offentliga sektorn $i$ debat och opinion. Stockholm: Svensk informations mediecenter, 1991 .

5 Nilsson L. Offentlig sektor och privatisering 1986-1996. In Holmberg S, Weibull L, eds. Ett missnöjt folk? -SOMundersökningen 1996. Gothenburg: SOM-rapport no 18, 1997.

6 Svallfors S. The middle class and welfare state retrenchment: attitudes to Swedish welfare policies. In: Svallfors S, TaylorGooby P, eds. Reactions to state retrenchment (in press).

7 Möller T. Brukare och klienter $i$ välfärdsstaten. Om missnöje och påverkansmöjligheter inom barn-och äldreomsorg. Stockholm: påverkansmojligh

8 Kangas OE. Interest mediation and popular will. In: Svallfors $\mathrm{S}$, ed. In the eye of the beholder. Opinions on welfare and justice in comparative perspective. Umeå: Impello, 1995:52-9.

9 Thorslund M, Bergmark Å, Parker MG. Difficult decisions on care and services for elderly people: the dilemma of setting priorities in the welfare state. Scandinavian fournal of Social Welfare 1997; 6:197-206.

10 Hollander A. Legal strategies to improve equality and welfare for disabled in Sweden. Fournal of the Allan Roeher Institute (in press).

11 Johansson L. Elderly care policy, formal and informal care, the Swedish case. Health Policy 1991;18:231-42.
12 OECD. Caring for frail elderly people. Policies in evolution. Social Policy Studies No 19. France: OECD, 1996.

13 National Board of Health and Welfare. Fämförelsetal för socialtiänsten 1996. Stockholm: Modin Tryck, 1997.

14 The Swedish Social Ministry. Välfärdsfakta social 1997-10-01. Stockholm: LA-Sekretariatet, 1997.

15 National Board of Health and Welfare. Äldreuppdraget, Arsrapport 1997. Stockholm: NBHW, 1998.

16 Bergmark Å. Prioriteringar i socialtjänsten - rättvisa och ekonomi. Stockholm: Stockholm University, Department of Social Work, 1995.

17 OECD. National accounts 1979-1992. Paris: OECD, 1994.

18 Callabresi G, Bobbit P. Tragic choices. New York: Norton, 1978.

19 Wolf J. An introduction to political philosophy. Oxford: Oxford University Press, 1996.

20 Frankena WK. Perspectives on morality. Notre Dame: University of Notre Dame Press, 1976.

21 Rawls J. A theory of justice. Cambridge: Harvard University Press, 1971.

22 Sen A. Inequality reexamined. Oxford: Oxford University Press, 1992.

23 Braybrooke D. Meeting needs. Princeton NJ: Princeton University Press, 1987.

24 Bradshaw J. The conceptualization and measurement of need. A social policy perspective. In: Popay J, Williams G, eds. Researching people's health. London: Routledge, 1994.

25 Wesearching people's health. London: Routledge, 1994.

26 Daniels N. Am I my parents' keeper? New York: Oxford University Press, 1998.

27 Nozick T. Anarchy, state and utopia. New York: Basic Books, 1974.

28 Bergmark Å. From reforms to rationing? Current allocative trends in social services in Sweden. Scandinavian fournal of Social Welfare 1997;6:74-81.

29 Thorslund M, Parker MG. Strategies for an ageing population: expanding the priorities discussion. Ageing and Society: 1995; 15:199-217. 